Recebido em: 15/04/2021. Aprovado em: 22/07/2021. Publicado em: 20/08/2021

Processo de Avaliação: Double Blind Review - SEER/OJS

e-ISSN: 2359-5876

https://doi.org/10.48075/comsus.v8i1.25675

\title{
Agricultura orgânica e familiar: concepções, políticas e aspectos legais
}

\section{Organic family farming: conceptions, politics and legal aspects}

Antônio Soares Júnior da Silva ${ }^{1}$

Demóstenes Dantas Vieira ${ }^{2}$

Sofia Bonfim Alves Palhares ${ }^{3}$

Maria Clara Coutinho Macedo ${ }^{4}$

Samuel Hübner ${ }^{5}$

\section{RESUMO}

Este trabalho, de cunho bibliográfico e pesquisa documental, propõe uma discussão acerca das concepções de agricultura familiar e produção orgânica. Para tanto, utilizamos as contribuições de Ormond (2002), Azevedo (2012), Wanderley (1999/2000), Saquet (2017), dentre outros. A pesquisa dedica-se também a analisar as políticas públicas e os aspectos legais acerca da produção orgânica no país. Para tanto, realizamos uma análise documental da Lei no 10.831/2003, do Decreto no 6.323/2007 e das Instruções Normativas - INs do Ministério da Agricultura, Pecuária e Abastecimento - MAPA, a saber: a IN no 19/09, que delineia os mecanismos de controle e formas de organização; a IN no 18/09, alterada pela IN no 24/11, sobre processamento; a IN no 17/09, acerca do extrativismo sustentável orgânico e, por fim, a IN n 50/09, sobre o selo federal do Sistema Brasileiro de Avaliação de Conformidade Orgânica - SisOrg. Os resultados apontam para importância da agricultura familiar para o desenvolvimento das comunidades locais e sugere que a produção orgânica tem potencial de crescimento em face das controvérsias alimentares da vida contemporânea.

Palavras-chave: Agricultura Familiar; Produção Orgânica; Aspectos legais.

\section{ABSTRACT}

This study uses a bibliographic and documentary methodology. It proposes a discussion on the concepts of family farming and organic production. For that, we used the contributions of Ormond (2002), Azevedo (2012), Wanderley (1999/2000), Saquet (2017), among others. The research is also dedicated to analyzing public policies and legal aspects of organic production in the country. For this purpose, a documentary analysis of Law No. 10.831 / 2003, Decree No. 6323 / 2007 and Normative Instructions - INs of the Ministry of Agriculture, Livestock and Supply - MAPA was carried out, namely: IN No. 19/09, which provides for the mechanisms of control and forms of organization; IN no 18/09, amended by IN no 24/11, on processing; IN no 17/09, on sustainable organic extractivism and, finally, IN no 50/09, on the federal seal of the Brazilian System of Organic Conformity Assessment - SisOrg. The results point to the importance of family farming for the development of local communities and suggest that organic production has growth potential due to the food controversies of contemporary life.

Key words: Family Agriculture; Organic Production; Legal Aspects

Cite as: (APA) Silva, A. S. J., Vieira, D. D., Palhares, S. B. A., Macedo, M. C. C., \& Hübner, S. (2021). Agricultura orgânica e familiar: concepções, políticas e aspectos legais. Revista Competitividade $e$ Sustentabilidade, 8(1), 88-97.

\footnotetext{
${ }^{1}$ Instituto Federal de Educação, Ciência e Tecnologia do Paraná - IFPR. E-mail: antonio.silvajunior@ifpr.edu.br

2 Instituto Federal de Educação, Ciência e Tecnologia do Rio Grande do Norte - IFRN. E-mail: demostenes.vieira@ifrn.edu.br

${ }^{3}$ Instituto Federal do Triângulo Mineiro - IFTM. E-mail: sofia_bomfim@yahoo.com.br

${ }^{4}$ Universidade Federal de Minas Gerais - UFMG. E-mail: clara.macedosl@hotmail.com

${ }^{5}$ Secretaria Municipal de Educação de Venâncio Aires - SMVA. E-mail: jacksam17@yahoo.com.br
} 
Silva, A. S. J., Vieira, D. D., Palhares, S. B. A., Macedo, M. C. C., \& Hübner, S. (2021). Agricultura orgânica e familiar: concepções, políticas e aspectos legais. Revista Competitividade e Sustentabilidade

\section{INTRODUÇÃO}

A agricultura familiar e a produção orgânica são temáticas que têm suscitado diversos interesses na sociedade. A agricultura familiar caracteriza-se fundamentalmente pelo trabalho familiar na exploração agropecuária e pela propriedade dos meios de produção. A princípio, parte-se do pressuposto de que o objetivo da agricultura orgânica é trabalhar de forma sinestésica com sistemas agrícolas complexos, proporcionando interações ecológicas correlacionadas entre os componentes biológicos, ocasionando a possibilidade de fertilizarem o solo, a produtividade e a proteção das culturas.

Em vista disso, adotamos como objetivo geral analisar as concepções acerca da produção orgânica e agricultura familiar. Por sua vez, os objetivos específicos consistem em refletir sobre a agricultura orgânica como um sistema de gerenciamento científico da produção agrícola e analisar os aspectos legais referentes à produção orgânica no país.

Vale salientar a relevância desse estudo, tendo em vista que o mesmo pode subsidiar políticas públicas para o desenvolvimento da agricultura familiar e da produção orgânica, além de contribuir para o aprofundamento e expansão desse modelo de agricultura para diversas comunidades locais e cooperativas distribuídas pelo país.

\section{CONSIDERAÇÕES SOBRE A AGRICULTURA FAMILIAR}

A agricultura familiar é parte fundamental na história e no desenvolvimento de nosso país. A agricultura e a agropecuária familiar têm um papel social com demandas gigantescas do ponto de vista econômico, e consequentemente, na promoção da distribuição de renda e da melhoria da qualidade de vida daqueles que vivem e produzem na zona rural.

Conforme Wanderley (2000) a importância da agricultura familiar tem sido reconhecida oficialmente, passando a ser analisada e fomentada no intuito de promover uma forma de agricultura alternativa ao padrão econômico aplicado à agricultura brasileira, que exclui e segrega a maioria dos produtores familiares. Assim sendo, a agricultura familiar passa a se afirmar como uma categoria expressiva no meio rural brasileiro. Do ponto de vista teórico, a análise acadêmica da produção familiar no Brasil pode ser sintetizada em duas vertentes principais, como afirma Marafon (2006, p. 18):

uma que centra a análise na categoria Agricultura Familiar, derivado, sobretudo, do estudo elaborado conjuntamente pela FAO/INCRA (1994) e que passou a orientar as políticas de desenvolvimento rural implementadas pelo Estado Brasileiro; a outra, que preconiza a atualidade e eficácia do conceito de campesinato para a análise da produção em base familiar no Brasil, e que tem na luta pelo acesso à terra o eixo fundamental de análise.

Segundo Wanderley (1999), a agricultura familiar é conceito amplo e genérico que incorpora uma gama de situações distintas e próprias. Considerando nesta interface o campesinato como parte correspondente a uma dessas formas específicas dessa agricultura. Todavia, existe um consenso de estudiosos afirmando que "a produção familiar se caracteriza pelo trabalho familiar na exploração agropecuária e pela propriedade dos meios de produção" (MARAFON, 2006, p. 19).

A agricultura de propriedade familiar tem como características primordiais, a relação 
Silva, A. S. J., Vieira, D. D., Palhares, S. B. A., Macedo, M. C. C., \& Hübner, S. (2021). Agricultura orgânica e familiar: concepções, políticas e aspectos legais. Revista Competitividade e Sustentabilidade

onde a gestão e o trabalho em estabelecimentos estão intimamente ligados. Nesse sentido, os meios de produção pertencem à família, e o trabalho é exercido por esses mesmos proprietários em uma área relativamente pequena ou média (MARAFON, 2006).

À vista disso, ressaltamos os estudos da FAO/INCRA (1994) que contribuíram para o estabelecimento do Programa Nacional de Produção Familiar (PRONAF). O trabalho produziu uma classificação dos agricultores familiares brasileiros, conforme quadro 1.

Quadro 1: Classificação dos Agricultores Familiares.

\begin{tabular}{|l|l|}
\hline Consolidados & $\begin{array}{l}\text { Produtores considerados empresários do setor, com boa liderança } \\
\text { nas comunidades. Buscam assistência técnica e creditícia, } \\
\text { possuindo bom poder de análise e gerenciamento. Propriedades } \\
\text { geralmente menores de 100ha com concentração próxima a 50ha. }\end{array}$ \\
\hline Em Transição & $\begin{array}{l}\text { Produtores de menor esclarecimento do que os consolidados, que } \\
\text { buscam em menor intensidade a assistência técnica e creditícia, } \\
\text { possuindo médio poder de análise e gerenciamento. Propriedades } \\
\text { geralmente menores de 100ha com concentração próxima a 20ha. }\end{array}$ \\
\hline Periféricos ou de Subsistência & $\begin{array}{l}\text { Utilização do crédito rural nula ou incipiente, sem viabilidade } \\
\text { econômica para acesso. Dificuldades quanto ao gerenciamento da } \\
\text { propriedade. Considerado agricultor que mais se aproxima do do } \\
\text { camponês tradicional, em local onde a luta pela terra e contra as } \\
\text { perversidades do capitalismo se faz presente. Propriedades } \\
\text { geralmente menores de 50ha com concentração abaixo de 20ha. }\end{array}$ \\
\hline
\end{tabular}

Fonte: Veiga, 2001.

Ainda do ponto de vista histórico, dois acontecimentos foram determinantes para consolidação inicial da agricultura familiar no Brasil. O primeiro deles foi a realização do Censo Agropecuário (2006), que forneceu dados essenciais para a compreensão do potencial da agricultura familiar brasileira. $\mathrm{O}$ outro aspecto, extremamente relevante para agricultura familiar, foi a criação de um marco legal e as opções para sua identificação, quando em 24 de julho de 2006, foi sancionada a Lei no. 11.326, que estabelece as "diretrizes para a formulação da Política Nacional da Agricultura Familiar e Empreendimentos Familiares Rurais".

Dados do governo federal apontaram um crédito para o PRONAF em 2015 na casa de $\mathrm{R} \$ 28,9$ bilhões de investimento. Ainda segundo dados divulgados pelo PRONAF, a agricultura familiar é responsável por grande parte da cadeia produtiva que abastece o país, a saber: mandioca (87\%), feijão (70\%), carne suína (59\%), leite (58\%), carne de aves (50\%) e milho (46\%) dentre outros produtos.

\section{SOBRE A AGRICULTURA ORGÂNICA}

No século XIX, a partir da I guerra mundial ocorreram mudanças cruciais nos processos industriais e nos modelos de produção no mundo. No espaço rural, começaram incentivos para a implantação de novas técnicas e práticas com o objetivo de aumentar a produtividade. De acordo com Saquet (2017), o propósito da aplicação deste pacote foi promover a chamada revolução verde. A base desse modelo de produção fixou-se em quatro pressupostos: novas tecnologias desde o plantio até a colheita e a comercialização; uso intenso de sementes modificadas, de fertilizantes e de agrotóxicos.

$\mathrm{Na}$ prática, a implementação desenfreada deste modelo, tem produzido vários problemas de ordem social, econômica e principalmente ambiental. Pesquisas têm 
Silva, A. S. J., Vieira, D. D., Palhares, S. B. A., Macedo, M. C. C., \& Hübner, S. (2021). Agricultura orgânica e familiar: concepções, políticas e aspectos legais. Revista Competitividade e Sustentabilidade

constatado diversos problemas relacionados a contaminação dos recursos hídricos e dos animais; erosão; contaminação dos solos e redução da sua fertilidade natural; redução da biodiversidade; dependência de insumos químicos.

Trabalhos sobre os impactos ambientais, realizados na Europa, comparando a agricultura orgânica e a convencional apontaram, segundo Stolz et al. (apud Azevedo 2000, 137), que na primeira foram evidenciados aspectos positivos em termos de incrementos para o contexto ambiental e na melhoria da saúde pública. São eles:

[...] impactos sobre o ecossistema, sobre a qualidade do solo; conservação da fertilidade e estabilidade do sistema, além de maior controle da erosão; sobre as águas superficiais e profundas, resultando em baixas taxas de nitrato e ausência de poluição por pesticidas; clima e qualidade do ar e não utilização de agrotóxicos.

Diante da problemática decorrente do sistema de produção convencional, urge na atualidade pensar e aplicar um modelo sustentável. Em face disso, a agroecologia e a agricultura orgânica são alternativas que podem minimizar os impactos ambientais e sociais oriundos da chamada modernização da agricultura.

Gliessman (2001), afirma que no início do presente século, um grupo de ecologistas sugeriram a terminologia denominada agroecologia para designar a ecologia aplicada à agricultura. Surge nesse período, as bases de um novo conceito de produção agrícola. A característica central desse novo modelo é a produção realizada em áreas pequenas diversificadas ou em propriedades maiores com foco na monocultura.

Sendo assim, faz se necessário diferenciar a agroecologia do sistema de produção orgânica. Eles são tratados como similares, todavia, apresentam diferenças conceituais e práticas relevantes. Conforme Saquet (2017, p. 44):

A agroecologia dedica-se ao estudo das relações produtivas existentes entre a sociedade e a natureza, objetivando sempre a sustentabilidade ecológica, econômica, cultural, política e ética. As práticas se baseiam na pequena propriedade, na mão-de-obra familiar, em sistemas produtivos complexos e diversos, adaptados às condições locais e em redes regionais de produção e distribuição de alimentos.

A produção orgânica apresenta um viés no sentido de evitar de forma radical o uso de insumos químicos. Vale constar, que a produção não está limitada ou isenta de ser realizada no sistema de agricultura convencional ou na prática da monocultura. Considerando que o foco central é a produção diferenciada, consequentemente o produto pode apresentar valor de destaque no processo de comercialização.

O rural ganha outra dimensão na perspectiva de se repensar a relação da agricultura familiar orgânica com a melhoria da qualidade de vida. Sendo assim, ele pode ser analisado como um espaço preservado, de valores profundos, autêntico e rico em tradições. Hoje, o mesmo pode transforma-se em lugar de vida, de promoção social, de produção agrícola ou econômica (BRUNO JEAN apud WANDERLEY, 2000).

Azevedo (2012), afirma que a agricultura familiar orgânica vinculada à dimensão ambiental e cultural, configura-se como uma estratégia para reintrodução natural no espaço rural e nos sistemas de produção agrícolas. Tal relação só é possível porque este modelo de 
Silva, A. S. J., Vieira, D. D., Palhares, S. B. A., Macedo, M. C. C., \& Hübner, S. (2021). Agricultura orgânica e familiar: concepções, políticas e aspectos legais. Revista Competitividade e Sustentabilidade

produção respeita os princípios naturais dos ecossistemas envolvidos e valoriza a cultura local rural. Nesse contexto, há uma reaproximação dos sujeitos do processo com a "consciência de que a natureza é parte da essência humana" (AZEVEDO, 2012, p. 137).

Ressalta-se também que a agricultura familiar urbana contribui positivamente e diretamente para melhoria da qualidade de vida do meio urbano. Primeiro pelo fato de que esse modelo de produção disponibiliza alimentos mais saudáveis. Segundo porque agricultura familiar orgânica apresenta-se com a possibilidade de reorganização social no meio rural, contribuindo de forma efetiva na qualidade dos empregos e na diminuição progressiva da violência no campo e na cidade.

À vista disso, a agricultura familiar orgânica tende a se estabelecer como espaço de elevação da qualidade de vida para coletividade, rural ou urbana. Todavia, há uma condicionante, ou seja, o sistema produtivo adotado deve priorizar algumas premissas como afirma Azevedo (2012, p.137) "preservar o meio ambiente, dignificar socialmente o agricultor, valorizar a cultura local e o saber tradicional e produzir alimentos saudáveis".

Para Panitchpakdi (2011), a produção orgânica é apropriada para os agricultores familiares que estatisticamente constituem a maioria dos pobres no mundo. Pesquisas realizadas na América Latina, Ásia e África mostram que os agricultores familiares que optam pela produção orgânica recebem mais que os agricultores convencionais. Um trabalho desenvolvido pela Conferência das Nações Unidas sobre o Comércio e Desenvolvimento e do Programa das nações Unidas para o Meio Ambiente, investigou 114 núcleos no continente africano e constatou que a transição das fazendas para o sistema orgânico conduz a um aumento na produtividade em torno de $116 \%$.

\section{AGRICULTURA ORGÂNICA E CONHECIMENTO CIENTÍFICO}

A caracterização da agricultura/produção orgânica como ciência, tem início a partir da pesquisa do inglês Albert Howard, datada do início da década de 1920. Howard viajou para Índia, onde analisou de forma criteriosa as práticas agrícolas de compostagem e adubação orgânica utilizadas pelos agricultores daquela região. Após as observações necessárias, o mesmo decidiu compilar tais dados num livro, no qual deu o título de "Um testamento agrícola", publicado em 1940.

Enquanto isso, na França, o estudioso Claude Aubert começou a difundir os trabalhos relacionados as práticas da agricultura biológica. As principais características abordadas pelo cientista eram: a prática da rotação de culturas, o uso dos adubos verdes, estercos, restos de culturas, palhas e outros resíduos vegetais ou animais, bem como controle natural de pragas e doenças. O trabalho realizado por Aubert constitui-se na literatura como um marco estrutural para promoção da agricultura orgânica.

Em 1924, na Alemanha Rudolf Steiner, institui as bases centrais da agricultura biodinâmica, que tem como eixo estruturante a harmonia e o equilíbrio da unidade produtiva (terra, plantas, animais e o homem) usando como referência as influências do sol e da lua.

No Japão, Mokiti Okadana, na década de 1930, difundiu a filosofia de uma agricultura diferenciada, agora denominada por ele como agricultura natural. Vale ressaltar a importância dada por Okadana sobre a existência de espírito e sentimento em todos os seres vivos, sejam eles de origem vegetal ou animal. Já, em 1971 na Austrália, Bill Mollison difundiu o conceito de permacultura, modelo que também visualiza uma agricultura integrada harmonicamente com o ambiente (ORMOND, 2002).

Outro ponto importante para consolidação e valorização da produção orgânica no 
Silva, A. S. J., Vieira, D. D., Palhares, S. B. A., Macedo, M. C. C., \& Hübner, S. (2021). Agricultura orgânica e familiar: concepções, políticas e aspectos legais. Revista Competitividade e Sustentabilidade

mundo, foi o início do processo de comercialização dos produtos oriundos desse novo sistema de produção na Europa. Nesse aspecto, ocorreu o crescente interesse e uma diversidade de produtos no mercado. Segundo Ormond (2002), o movimento se fortaleceu no final da década de 1980, tendo seu ápice de crescimento em meados dos anos 1990, com a criação do programa fomentado pelo Council Regulation da Comunidade Económica Europeia (CEE) no documento 2092/91, que estabeleceu as normas básicas e os padrões de produção, processamento, comercialização e importação de produtos orgânicos de origem vegetal e animal nos seus estados membros.

No Brasil, os primeiros adeptos da produção orgânica foram grupos ligados a questões filosóficas que tinham como pressupostos básicos o retorno do ser humano ao contato com a terra em contraposição aos hábitos alimentares consumistas da sociedade capitalista vigente.

As primeiras práticas produtivas e comerciais do sistema orgânico no Brasil foram estabelecidas por cooperativas (Rio de Janeiro - Coonatura, e Rio Grande do Sul - Coomeia), no final da década de 1970. Organizações Não Governamentais (ONGs) apoiaram os agricultores no processo de comercialização em feiras e entregas de cestas em domicílio. Aproximando assim, o produtor do consumidor, o que ocasionava uma relação de confiança e credibilidade (FONSECA, 2000).

A Lei 10.831, de 23 de dezembro de 2003, contribuiu de forma significativa para o avanço e a consolidação da agricultura/produção orgânica. Apesar de sua regulamentação, no entanto, ter ocorrido apenas em 27 de dezembro de 2007 com a publicação do Decreto no 6.323, a lei trouxe clareza e definição para os processos que envolvem a cadeia produtiva.

\section{A PRODUÇÃO ORGÂNICA E OS INSTRUMENTOS LEGAIS NO BRASIL}

Atualmente, práticas agrícolas mais sustentáveis têm sido estimuladas no intuito de promover o equilíbrio envolvendo as cadeias produtivas e a conservação e preservação do meio ambiente. Por conseguinte, se faz necessário discutir novos conceitos de produção agrícola fundamentados na conservação do solo, diversificação de culturas, reciclagem de nutrientes, uso sistemático de adubos orgânicos e outras práticas alternativas (SALMI et al., 2006).

O sistema de cultivo orgânico configura-se como uma opção para atender as demandas de uma agricultura mais sustentável, valorizando e respeitando o meio ambiente. De acordo com Altieri (2001), o propósito básico da agricultura orgânica é trabalhar de forma sinestésica com sistemas agrícolas complexos, proporcionando interações ecológicas correlacionadas entre os componentes biológicos, ocasionando a possibilidade dos mesmos criarem, eles próprios, a fertilidade do solo, a produtividade e a proteção das culturas.

No Brasil, uma referência norteadora para a agricultura orgânica foi a criação da Instrução Normativa 007/99, do Ministério da Agricultura, Pecuária e Abastecimento (MAPA), que conceituou como

sistema orgânico de produção agropecuária e industrial todo aquele em que se adotam tecnologias que otimizem o uso dos recursos naturais e socioeconômicos, respeitando a integridade cultural e tendo por objetivo a auto sustentação no tempo e no espaço, a maximização dos benefícios sociais, a minimização da dependência de energias não-renováveis e a eliminação do emprego de agrotóxicos e outros insumos artificiais tóxicos, Organismos Geneticamente 
Silva, A. S. J., Vieira, D. D., Palhares, S. B. A., Macedo, M. C. C., \& Hübner, S. (2021). Agricultura orgânica e familiar: concepções, políticas e aspectos legais. Revista Competitividade e Sustentabilidade

Modificados (OGM)/transgênicos ou radiações ionizantes em qualquer fase do processo de produção, armazenamento e de consumo, e entre os mesmos privilegiando a preservação da saúde ambiental e humana, assegurando a transparência em todos os estágios da produção e da transformação (Instrução Normativa 007/99, MAPA).

A IN 007/99 estabelece os critérios básicos visando o oferecimento de "produtos saudáveis e de elevado valor nutricional, isentos de qualquer tipo de contaminantes que ponham em risco a saúde do consumidor, do agricultor e do meio ambiente". Por conseguinte, visa preservar e ampliar a "biodiversidade dos ecossistemas, natural ou transformado, em que se insere o sistema produtivo; a conservação das condições físicas, químicas e biológicas do solo, da água e do ar e o fomento da integração efetiva entre agricultor e consumidor final de produtos orgânicos", incentivando a "regionalização da produção desses produtos orgânicos para os mercados locais."

Segundo o regulamento Council Regulation da Comunidade Econômica Europeia (CEE) 2092/91, as plantas comestíveis ou partes comestíveis de plantas (frutos, sementes, talos, folhas, raízes etc.) que cresçam de forma espontânea em áreas naturais, florestas e áreas agrícolas são consideradas um produto orgânico, quando as áreas onde são encontradas não tenham sido tratadas com produtos químicos e/ou sintéticos, durante três anos precedentes à colheita. A colheita não poderá afetar a estabilidade do ecossistema nem prejudicar a conservação das espécies nativas (ORMOND, 2002).

Atualmente, o instrumento legal que norteia a agricultura/produção orgânica no Brasil é a Lei 10.831, de 23 de dezembro de 2003, que dispõem sobre a cultura e a comercialização dos produtos orgânicos. Outros instrumentos legais também são importantes como o decreto № 6.323/07 e as instruções normativas do MAPA, a saber: $\mathrm{N}$ ㅇ 19/09 (mecanismos de controle e formas de organização); $N$ 18/09, alterada pela IN 24/11 (processamento); N 17/09 (extrativismo sustentável orgânico); N o 50/09 (selo federal do Sistema Brasileiro de Avaliação de Conformidade Orgânica SisOrg); $N \cong 46 / 11$ (produção vegetal e animal); $N \cong$ 37/11 (cogumelos comestíveis); $\mathrm{N}$ ㅇ 38/11 (sementes e mudas orgânicas); $\mathrm{N}$ o 28/11 (produção de organismos aquáticos).

O quadro abaixo mostra quais são os critérios de comercialização de produtos no Brasil considerados como "Orgânicos" e os procedimentos para os produtores se regularizarem.

Quadro 2: Regularização da Produção Orgânica.

\section{Como se regularizar?}

Obter certificação por um Organismo da Avaliação da Conformidade Orgânica (OAC) credenciado junto ao

Ministério da Agricultura, Pecuária e Abastecimento - MAPA; ou

Organizar-se em grupo e cadastrar-se junto ao MAPA para realizar a venda direta sem certificação.

\section{Qual a diferença entre ter e não ter a certificação?}

Quando o produtor se cadastrou apenas para venda direta sem certificação, não pode vender para terceiros, só na feira (ou direto ao consumidor) e para as compras do governo (merenda e CONAB).

Quando o produto é certificado, pode vender seu produto em feiras, mas, também, para supermercados, lojas, restaurantes, hotéis, indústrias, internet etc. 
Silva, A. S. J., Vieira, D. D., Palhares, S. B. A., Macedo, M. C. C., \& Hübner, S. (2021). Agricultura orgânica e familiar: concepções, políticas e aspectos legais. Revista Competitividade e Sustentabilidade

Como saber se o produto é orgânico, mesmo?

Para vender na feirinha, o produtor sem certificação deve apresentar um documento chamado Declaração de Cadastro, que demonstra que ele está cadastrado junto ao MAPA e que faz parte de um grupo que se responsabiliza por ele. Neste caso, só o produtor, alguém de sua família ou de seu grupo pode estar na barraca, vendendo o produto. Essa Declaração deve ser mostrada sempre que o consumidor e a fiscalização pedirem. Já os produtos vendidos em mercados, supermercados, lojas, devem estampar o selo federal do SisOrg em seus rótulos, sejam produtos nacionais ou estrangeiros.

Se o produto for vendido a granel deve estar identificado corretamente, por meio de cartaz, etiqueta ou outro meio.

Os restaurantes, lanchonetes e hotéis que servem pratos orgânicos ou pratos com ingredientes orgânicos devem manter à disposição dos consumidores listas dos ingredientes orgânicos e dos fornecedores deste ingrediente.

O que acontece se uma loja expuser à venda um produto sem selo, cujo rótulo diz que é orgânico?

O produto será apreendido e a loja, avisada por escrito sobre os cuidados a tomar.

Quando o produto sem selo está em uma embalagem original, o responsável é sempre o produtor; neste caso, ele será autuado e poderá ser multado. Quando o produto estiver em outra embalagem, como da própria loja ou mercado, ou a granel (aberto),

respondem pela irregularidade tanto o produtor como o responsável pelo ponto de venda.

Que cuidados o comerciante pode tomar para ter certeza de que está adquirindo produtos verdadeiramente orgânicos?

A Nota Fiscal com a descrição do produto como orgânico não é plena garantia de procedência. O comprador deve exigir do produtor que os rótulos dos produtos venham com o selo federal do SisOrg. No caso de produtos não pré-embalados, como verduras e legumes, pode pedir cópia do certificado orgânico do produto e, mesmo, um outro documento chamado Declaração de Transação Comercial, que tanto o produtor como a certificadora podem emitir. Em todos os casos, o comprador pode consultar o Cadastro Nacional de Produtores Orgânicos, disponível no sítio do MAPA, na internet.

Sou produtor e quero me regularizar. Como faço?

A certificação pode ser obtida pela contração de uma Certificadora por Auditoria ou se ligando a um Sistema Participativo de Garantia - SPG, que deverá estar sob certificação de um Organismo Participativo de Avaliação da Qualidade Orgânica - OPAC.

No caso de contração da Certificadora por Auditoria, o produtor receberá visitas de inspeção inicial e periódicas e manterá obrigações perante o MAPA e a certificadora, com custo a ser estabelecido em contrato. Se o produtor descumprir as normas, a certificadora retira seu certificado e informa ao MAPA. Procure na lista de Entidades Regularizadas as Certificadoras por Auditoria já credenciadas pelo MAPA.

No caso da certificação por OPAC, o produtor deve participar ativamente do grupo ou núcleo a que estiver ligado, comparecendo a reuniões periódicas e o próprio grupo garante a qualidade orgânica de seus produtos, sendo que todos tomam conta de todos e respondem, juntos, se houver fraude ou qualquer irregularidade que não apontarem e corrigirem. Se o produtor não corrigir, o grupo deve excluí-lo, cancelar o certificado e informar ao MAPA. Procure na lista de Entidades Regularizadas os OPAC já credenciados pelo MAPA. Caso o interesse seja apenas pela venda direta ou institucional, os produtores podem formar uma Organização de Controle Social - OCS.

Fonte: Adaptado de Ministério da Agricultura, Pecuária e Abastecimento, 2017. http://www.agricultura.gov.br/assuntos/sustentabilidade/organicos/regularizacao-da-producao acesso em 23 de setembro de 2017.

\section{CONSIDERAÇÕES FINAIS}

O presente trabalho propôs a análise das concepções acerca da produção orgânica e agricultura familiar, assim como investigar a origem da agricultura orgânica e familiar; refletir sobre a agricultura orgânica como uma ciência e, por fim, analisar os aspectos legais referentes à produção orgânica no país.

A bibliografia consultada aponta para uma concepção de agricultura orgânica e familiar como uma alternativa aos padrões de produção convencional centrada na produção, no uso 
Silva, A. S. J., Vieira, D. D., Palhares, S. B. A., Macedo, M. C. C., \& Hübner, S. (2021). Agricultura orgânica e familiar: concepções, políticas e aspectos legais. Revista Competitividade e Sustentabilidade

de agrotóxico e sem preocupação com o uso sustentável dos recursos naturais. Nesse sentido, tanto a agricultura orgânica como a agricultura familiar estão comprometidas com a qualidade dos alimentos, tendo em vista a saúde dos seres humanos. Assim também, preocupam-se com o desenvolvimento de estratégias de produção ligadas à atividade local e à sustentabilidade.

Em vista disso, a produção orgânica e agricultura familiar têm sido assunto recorrente na literatura especializada. Conforme verificado no aporte teórico, o estudo científico da agricultura orgânica e familiar tem início na década de 20 do século passado e tem se constituído como importante campo do conhecimento dentro das Ciências Agrárias e Ciências Sociais, tendo em vista o caráter inter/transdisciplinar do fenômeno que comporta características ligadas não só a produção e consumo, mas aos aspectos da vida social que o caracterizam, tais como as crenças, saberes, formação, trabalho etc.

Quanto aos aspectos legais, vale destacar a Lei 11.326, que estabelece as "diretrizes para a formulação da Política Nacional da Agricultura Familiar e Empreendimentos Familiares Rurais", um marco importante no que se refere à regulamentação e políticas públicas voltadas para o desenvolvimento da agricultura orgânica e familiar, destacando-se também a Lei 10.831 que dispõe sobre a agricultura orgânica, dando algumas providências. Por fim, destacase a sua regulamentação, efetivada em 27 de dezembro de 2007 com a publicação do Decreto № 6.323 .

\section{REFERÊNCIAS}

Altieri, M. (2001). Agroecologia, a dinâmica produtiva da agricultura sustentável. Universidade Federal do Rio Grande do Sul: Editora URGS

Azevedo, E. D. (2012). Alimentos orgânicos: ampliando os conceitos de saúde humana e social. São Paulo: Senac.

Brasil. Constituição (1988). Constituição da República Federativa do Brasil. Brasília: Centro Gráfico.

Embrapa. Centro Nacional de Pesquisa de Solos - Rio de Janeiro, RJ. (2006). Sistema brasileiro de classificação de solos. 2. ed. - Rio de Janeiro: EMBRAPA-SPI.

Fonseca, M. F. A. C. (2000). A construção social do mercado de alimentos orgânicos: Estratégias dos diferentes atores da rede de produção e comercialização de frutas, legumes e verduras (FLV) in natura no estado do Rio de Janeiro. Dissertação de Mestrado. Universidade Federal Rural do Rio de Janeiro UFRRJ, Rio de Janeiro.

Gliessman, S. R. (2001). Agroecologia: Processos ecológicos em agricultura sustentável. 2ed. Porto Alegre: Ed. UFRGS.

Marafon, Glaúcio J. (2006). Agricultura familiar, pluriatividade e turismo rural: reflexões a partir do território fluminense. CAMPO-TERRITÓRIO: Revista de Geografia Agrária [Versão eletrônica], v. 1, n. 1, p. 17-60. 
Silva, A. S. J., Vieira, D. D., Palhares, S. B. A., Macedo, M. C. C., \& Hübner, S. (2021). Agricultura orgânica e familiar: concepções, políticas e aspectos legais. Revista Competitividade e Sustentabilidade

Marini, E. (2010). Nucleação de comunidades escolares tradicionais no município de Nova Petrópolis: perspectivas interculturais no processo de escolarização. Dissertação de Mestrado, Universidade de LaSalle, Canoas.

Ormond, J. G. P et al. (2002). Agricultura orgânica: quando o passado é futuro. BNDES Setorial, Rio de Janeiro, n. 15, p. 3-34.

Panitchpakdi, Supachai. (2011). Agricultura orgânica para produzir mais e melhor. Plurale [Versão eletrônica], n. 1, p.-1-2.

Programa Nacional de Fortalecimento da Agricultura Familiar (Pronaf). (2017). Agricultura Familiar produz $70 \%$ dos Alimentos Consumidos por Brasileiros Brasília: Pronaf.

Salmi, G. P.; Salmi, A. P. \& Abboud, A. C. S. (2006). Dinâmica de decomposição e liberação de nutrientes de genótipos de guandu sob cultivo em aleias. Pesq. Agropec. Bras., 41:673678, 2006.

Saquet, M.A; De Souza, P. \& Dos Santos, R. A. (2017). Agricultura familiar agroecológica em itapejara d'oeste-pr. Revista Da Anpege, v. 6, n. 06, p. 43-57.

Veiga, J. E. (1991). O desenvolvimento agrícola: uma visão histórica. São Paulo: Editora da Universidade de São Paulo: HUCITEC.

Wanderley, M. N. B. (1999). Raízes históricas do campesinato brasileiro. In: TEDESCO, J. C. (Org.). Agricultura familiar: realidade e perspectivas. Passo Fundo: EDUPF.

Wanderley, M. N. B. (2000). A valorização da agricultura familiar e a reivindicação da ruralidade no Brasil. In.: Anais do XXXVIII Encontro Brasileiro de Economia e Sociologia Rural. Rio de Janeiro: SOBER. 